\title{
Erosion in the Healthcare Safety Net: Impacts on Different Population Groups
}

\author{
Lee Mobley $^{*}, 1$, Tzy-Mey Kuo ${ }^{1}$ and Gloria J. Bazzoli ${ }^{2}$ \\ ${ }^{I}$ RTI International, 3040 Cornwallis Rd., P.O. Box 12194, RTP, NC 27709-2194, USA \\ ${ }^{2}$ Department of Health Asministration, Virginia Commonwealth University, P.O. Box 980203, Richmond, VA 23298- \\ 0203, USA
}

\begin{abstract}
Safety net hospitals (SNHs) have played a critical role in the U.S. health system providing access to health care for vulnerable populations, in particular the Medicaid and uninsured populations. However, little research has examined how access for these populations changes when contraction of the safety net occurs. Institutional policies, such as hospital closure or ownership conversion, could affect the supply of minority health care providers, thus exacerbating disparities in outcomes. We use multilevel logistic modeling of person-level hospital discharge data to examine the effects of contractions in the California safety net over the period of 1990-2000 on access to care as measured by changes in ambulatory care sensitive condition (ACSC) admissions, using geographic methods to characterize proximity to a contraction event. We found that presence of a contraction event was associated with a statistically significant increase in the predicted probability of impeded access, with an increase of about $1 \%$ for Medicaid-insured populations and about 4$5 \%$ for the uninsured. The Medicaid-insured group also maintained the highest rates of ACSC admissions over time, suggesting persistent access problems for this vulnerable group. This research is timely given continued budget problems in many states, where rising unemployment has increased the number of Medicaid enrollees by 6 million and uninsured individuals by 1.5 million, increasing pressure on remaining SNHs.
\end{abstract}

Keywords: Healthcare safety net, safety net contraction, access to care, ambulatory care sensitive condition, health disparities.

\section{INTRODUCTION}

Safety net hospitals (SNHs) have played a critical role in the U.S. health system by providing access to health services for vulnerable populations, especially Medicaid, lowincome, and uninsured individuals as well as racial or ethnic minorities. By virtue of the tax appropriations they receive, public hospitals are legally mandated by local or state public officials to accept all patients seeking treatment, regardless of the patient's ability to pay or insurance status [1]. In addition, the Institute of Medicine (IOM) noted that other hospitals, in particular some nonprofit institutions, have adopted missions to provide a significant amount of care to the uninsured, Medicaid, and other vulnerable patients. Furthermore, 20 states in the United States have adopted community benefit requirements that mandate nonprofit hospitals to provide some charity care given their tax exempt status [2].

SNHs are most often located in neighborhoods where the poor and racial or ethnic minorities tend to reside. In part, this reflects public policy decisions to financially support health care organizations operating in what would otherwise be medically underserved areas, and also may reflect the decisions of poor and minority individuals to live near safety net institutions if they lack access to other sources of care [3, 4]. SNHs usually offer an array of public health and

*Address correspondence to this author at the RTI International, 3040 Cornwallis Rd., P.O. Box 12194, RTP, NC 27709-2194, USA; Tel: 919-

541-7195; Fax: 919-541-7384; E-mail: 1mobley@rti.org specialty services used by vulnerable populations, including maternity care, neonatal intensive care units, burn units, psychiatric emergency care, and substance abuse services [57]. SNHs can also play an important role providing primary care or directing patients to sources of primary care. For some individuals covered by Medicaid and those lacking insurance, SNHs can become their usual source of primary care because physicians in the community may not accept them into their practices [1, 8-11]. Additionally, recent research suggests that due in part to the shortage of primary care physicians in some communities, even the insured are using hospital emergency departments to obtain non-urgent care that could be handled by physicians [12].

SNHs have been under great strain in recent years. Some of the forces affecting them are germane to any community hospital, most notably public- and private-payer efforts to constrain payment growth [13]. Although HMOs in the commercial sector have lost strength, they have grown in prominence in the Medicaid sector, steering patients away from SNHs and leaving them with a disproportionately uninsured patient mix [14-17]. In addition, the health services demand among Medicaid and indigent populations has been increasing. Medicaid enrollment increased by nearly 6 million people between the start of the recession in December 2007 and December 2009, while the number of uninsured individuals increased 1.5 million. ${ }^{1,2}$ During the

\footnotetext{
${ }^{1}$ Medicaid Enrollment: December 2009 Data Snapshot: http://www.kff.org/ medicaid/enrollmentreports.cfm

${ }^{2}$ http://facts.kff.org/chartbook.aspx?cb=55 The number of uninsured rose to
} 44.7 million by 2003 , and to 45 million by 2007 , which was then $18 \%$ of the 
recent economic downturn, each 1 percent rise in unemployment was expected to be associated with an increase of 1.1 million uninsured people [18].

Other pressures specific to safety net institutions include cutbacks in Medicare subsidies for medical education and disproportionate share hospital payments, and growing strain on Medicaid programs caused by ongoing state fiscal problems. Bazzoli et al. [19] found that core SNHs cut back on their provision of uncompensated care following the Medicaid cutbacks of the 1997 Balanced Budget Act. Mobley [16] found that there was a domino effect in some California communities when a public hospital closed, with uncompensated care becoming more concentrated in remaining public hospitals. As such, those individuals who depend most on safety net institutions may be facing fewer options for their care.

Institutional policies, such as SNH closure or ownership conversion, could affect the accessible supply of racial or ethnic minority health care providers, and thus exacerbate racial or ethnic disparities in access to care, health status, and outcomes. Although prior research has noted that hospital closures can provide benefits to communities though improved efficiency resulting from better utilization of remaining capacity and potentially higher quality due to the concentration of volume [20], it is important to note that most people receive their hospital care in facilities near their homes, especially in urban areas. Thus, closures and conversions could have a major impact on access to care for many individuals who live near these facilities as these institutions are a major resource for them in their communities.

This paper contributes to the literature in several ways. Although some studies have examined the hospital safety net and others have examined access and use of health services by vulnerable populations, little research has linked these two areas. The major goal of this paper is to explicitly link these two areas and to use distance relationships and usual travel patterns to characterize proximity of individuals to particular safety net contraction events. Proximity, race or ethnicity, and insurance type are interacted in models to identify how these relationships affect accessibility after contractions of the safety net occur. We measure access using a traditional measure that draws on complete hospital discharge data rather than patient self-report data describing access issues they might experience. We focus specifically on Medicaid caseload when defining SNHs, and interpret findings with a focus on this particular subgroup. We also control statistically for a rich set of ecological covariates not included in previous studies.

\section{Research questions of interest are:}

1. Are some population subgroups, in particular those covered by Medicaid, more deeply affected by the contraction of nearby safety net resources?

2. Over time, how does accessibility change for racial or ethnic subgroups with Medicaid and other types of insurance coverage?

non-elderly population. Sixteen states had rates higher than $18 \%$, with California among them at $20.4 \%$ uninsured in 2007. Between 2007-2008, the number of uninsured adults rose by 1.5 million: http://www.kff.org/uninsured/8004.cfm

\section{CONCEPTUAL MODEL}

The conceptual framework used in this study combines traditional access to care and health service utilization models with a unique understanding of the spatial and geographic components of access and utilization. Our model follows Khan and Bhardwaj [21], which builds on the classic Aday and Anderson [22] model, and extends it to include delineation of the various levels of influence (interpersonal, community, and policy level) in the socio-ecological environment [23, 24]. Fig. (1) presents a graphical depiction of the conceptual framework. The spatial interactions approach considers the characteristics of the person, characteristics of available providers, intervening socioecological environmental factors, and policy variables that can impact travel to, or utilization of, health facilities. The policy dimension studied is the contraction in safety net resources in a person's neighborhood. This conceptual model guided our selection of area contextual variables to include in the empirical modeling. We control statistically for commuting behavior, residential segregation/isolation, and cultural cohesion, in addition to area poverty and health system resources. The former are sources of variation in access to hospital care that have not been examined previously in the SNH literature.

\section{METHODS}

\section{Identification of the Hospital Safety Net}

Within the United States, general acute care hospitals have served as a cornerstone of the health care safety net [25]. There is no single universal approach that has been used in the research literature to identify SNHs. Some studies have focused exclusively on public hospitals as core safety net institutions, given the legal requirements that they must maintain an open door for all individuals [26-28]. Other studies have considered both public hospitals and urban academic medical centers as the primary safety net $[14,29$ 31]. Some researchers have recognized that communities lacking public hospitals or major academic centers often have committed nonprofit institutions serving as core SNHs and these studies used data on the annual amount of indigent care provided by these hospitals to assess safety net involvement $[6,7,19,25,29,32,33]$. A number of recent studies have focused primarily on public hospitals and a group of nonprofit hospitals with the latter selected based on providing a disproportionate share care to Medicaid populations in their local communities [4, 34].

Zwanziger and Khan [35] also examined the safety net involvement of hospitals, assessing such measures as the socioeconomic status (SES) in a hospital's service area, Medicaid intensity, and uncompensated care burden and market share. They noted that each approach identifies a somewhat different set of hospitals as core safety net institutions, and thus, argued that researchers align their research focus to their selected definition of SNHs. In this paper we base our SNH definition on Medicaid intensity, specifically the share of inpatient days coved by this payer in each state. Using the state mean of Medicaid share plus one standard deviation, we identified non-profit SNHs and included them with public hospitals as SNHs in each study state. Separate thresholds for urban and rural hospitals in each state were developed. Zwanziger and Khan also noted 


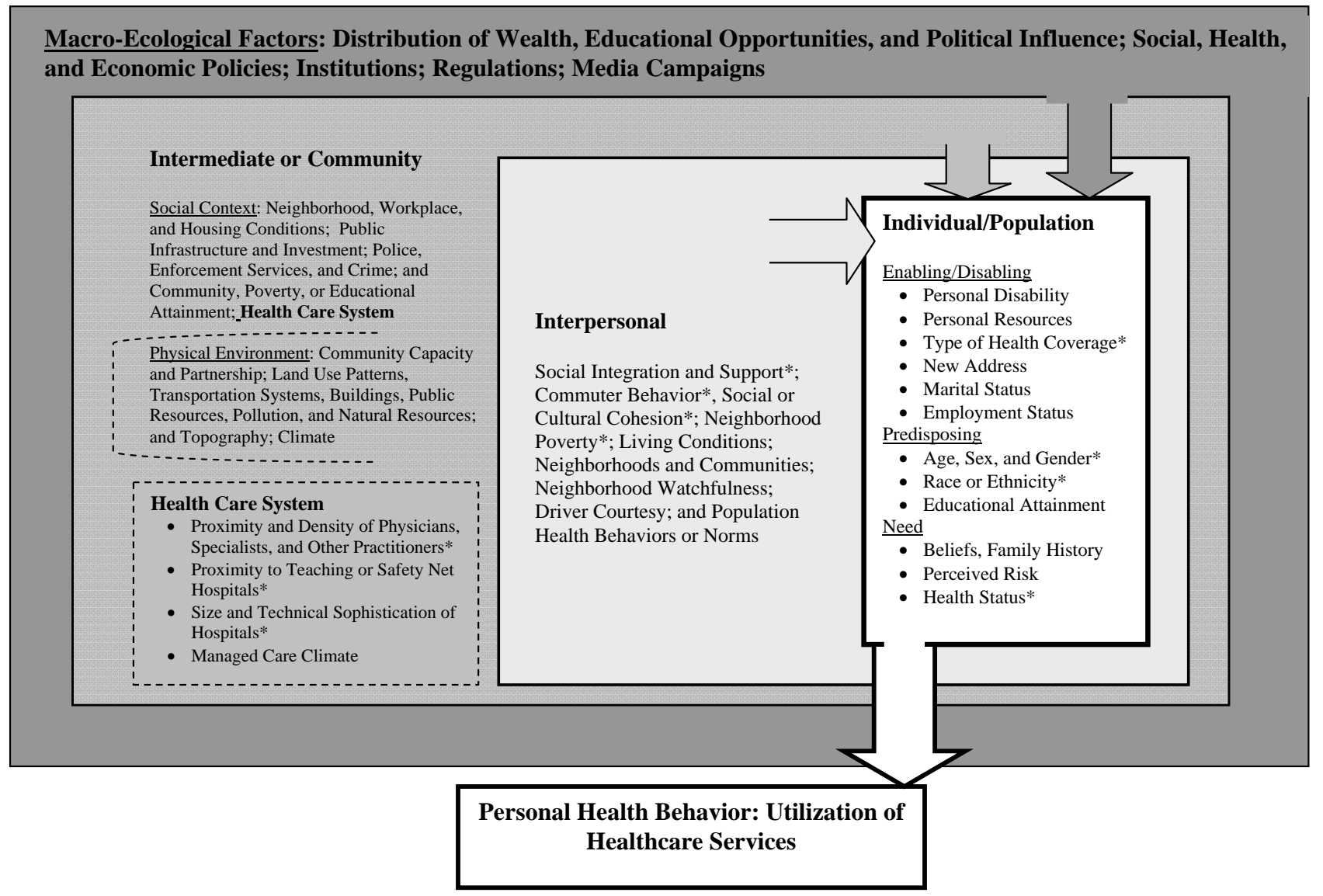

* Variables included in empirical model

Fig. (1). Spatial Interaction Model of the Utilization of Health Care Services.

that measures of SNH status may be unstable over time. Thus, we averaged two years of baseline data on Medicaid shares (1989-1990) to minimize the effect of atypical data or annual fluctuations in Medicaid caseload, so as to identify more stable indicators of SNH status. Following Zwanziger and Khan [35], we focus the discussion of our findings on the effect of SNH contractions on access to care for the Medicaid population, given our use of Medicaid caseload to identify non-profit SNHs.

California had a total of 418 short-term general medical/surgical hospitals in 1990, $114(27 \%)$ of which were SNHs, based on our approach for defining these institutions. In total, seven of these institutions closed and 18 more experienced ownership conversions, resulting in erosion of about $22 \%(25 / 114)$ of the SNH capacity in California during this decade. ${ }^{3}$ Many other non-SNHs closed over the study period, resulting in only 360 hospitals remaining operational in 2000.

\section{Access Measure}

The IOM [36] recommended that hospitalizations for ambulatory care-sensitive conditions (ACSCs) be used to examine disparities that reflect lack of access, because

\footnotetext{
${ }^{3}$ We focus on ownership conversions in which an initially public hospital
} becomes private or in which a private nonprofit SNH becomes for-profit.
ACSCs are thought to be preventable for individuals receiving good primary care and preventive care services. Several studies have examined determinants of person-level ACSC admissions given the IOM's 1993 recommendation to use these admissions as a critical measure of health care access. Generally, the studies have found mixed results about differences in ACSC admissions among black and white Medicare beneficiaries [37-40]. In one of the most comprehensive studies of disparities, Gaskin and Hoffman [41] looked at three population groups (whites, blacks, and Hispanics) and three age groups (children, working-age adults, and the elderly). The findings indicated that higher rates of ACSC hospitalization for Hispanic children, working-age blacks, and both black and Hispanic elderly persisted after controlling for patient health care needs, insurance coverage, and primary care physician availability.

Following existing practice [40, 42, 43], we group hospital discharges based on whether they were ACSCs or marker conditions (MCs). MCs require immediate urgent care, and are not likely to be access-sensitive. Thus, they serve as a basis of comparison and normalization for the effects of reduced access on ACSC admissions. We expect that $\mathrm{SNH}$ closure or ownership conversion will lead to an increase in ACSC admissions relative to MC admissions, especially for Medicaid patients near the affected SNH, 
Table 1. List of Ambulatory Care Sensitive and Marker Conditions Used to Select Hospital Discharge Records for Study

\begin{tabular}{|l|l|l|}
\hline \multicolumn{2}{|c|}{ Ambulatory Care Sensitive Conditions } & Marker Conditions \\
\hline \hline Angina & Hypertension & Acute myocardial infarction \\
\hline Asthma & Grand mal status and other epileptic convulsions & Fracture hip/femur \\
\hline Bacterial pneumonia & Hypoglycemia & Appendicitis with appendectomy \\
\hline Lower limb peripheral vascular disease (PVD) & Immunization-related and preventable conditions & Gastrointestinal obstruction \\
\hline Chronic obstructive pulmonary disease & Pulmonary or other tuberculosis & \\
\hline Congenital syphilis & Kidney/urinary infection & \\
\hline Congestive heart failure & Nutritional deficiencies & \\
\hline Dehydration-volume depletion & Pelvic inflammatory disease & \\
\hline Acute diabetic events & Iron deficiency anemia & \\
\hline Dental conditions & Cellulitis & \\
\hline Failure to thrive & Severe ear, nose, or throat infections & \\
\hline Gastroenteritis & Skin grafts with cellulitis or septicemia & \\
\hline
\end{tabular}

given that these institutions may play an important role in providing or directing these patients to primary care services.

The ACSC and MC definitions were originally developed by Billings et al. [44] and modified in subsequent work (Table 1). We use the primary diagnosis for identifying and categorizing relevant conditions as ACSC or marker. Following practices in recent research [43], admissions with both MC and ACSC diagnosis codes were assigned to marker admissions.

\section{Sample Data and Study Population}

We use California hospital discharge information for 1990 and 2000, years coinciding with the decennial census and a rich set of associated contextual variables. Although more recent discharge data were available for California, the state suppressed individual race or ethnicity after 2000. Discharge data are obtained from the Healthcare Cost and Utilization Project (HCUP) State Inpatient database (SID) of the Agency for Healthcare Research and Quality [45]. All short-term general medical/surgical hospitals and all discharges are included in the database for each year. For the analysis, we included all hospital discharges for patients with the primary diagnosis-related group (DRG) indicating an ACSC or MC admissions (Table 1), for patients aged 25 or older and with a valid ZIP code of address. Less than $5 \%$ of the sample was trimmed due to invalid ZIP code. In California, we started with over 2 million discharges in 1990, about 18.9 percent of which were ACSC or marker admissions. After exclusions, we had 422,067 observations in 1990 and 472,570 observations in 2000 .

In the analyses, we include person-specific characteristics and contextual information. Person-specific characteristics include age groups, race/ethnicity, gender, comorbidities, insurance type, and distance to the closest SNH that remained operational after any local safety net contraction events had occurred. We defined three binary indicators (D1, D2, or D3) of whether the closest closed/converted/merged
SNH (i.e., a contraction event) is located within these three consecutive distance bands of a person's home. The width of the bands is based on travel distances observed in the base period for all people discharged from hospitals and are defined as D1 (less than 6 miles), D2 (greater than 6 but less than 16 miles), and D3 (greater than 16 but less than 46 miles). These variables are defined in an iterative fashion so as to be mutually exclusive.

Contextual data include health system characteristics in the patient's neighborhood (county), characteristics of the local neighborhood, and characteristics of the hospital. Health system characteristics in the patient's neighborhood include primary care physicians, specialists, non-physician providers (nurses, physician assistants, residents, and interns in primary care), and were all expressed per capita and defined for the early and late period. Inpatient days per capita are included to reflect the supply of and demand for hospital resources in the area. Other characteristics of the local neighborhood include: percent poverty, 'neighborhood acculturation' proxied by percent recent foreign immigrants (1985-1990; 1995-2000), and 'commuter behavior' proxied by median commute time to work, defined for 1990 and 2000 at the zip code tabulation area (ZCTA level). ${ }^{4}$ We also include as a measure of 'social cohesion,' using an isolation index representing residential segregation for blacks and Hispanics. All of these local neighborhood characteristics are defined at the primary care service area (PCSA) level, which is smaller than the county. ${ }^{5}$ Characteristics of the hospital,

\footnotetext{
${ }^{4}$ The ZCTA boundaries are a 2000 census construct and contain one or more ZIP codes, representing postal delivery zones. Using these boundaries, ZIP codes with their centroids inside are assigned to unique ZCTAs. While the 2000 census data are provided at ZCTA aggregates, the 1990 census data are not. To obtain 1990 census data in the ZCTA footprints, we crosswalked the 1990 ZIP code centroids to the 2000 ZCTAs, obtained the 1990 ZIP code data provided by census, and aggregated it to reflect 1990 equivalents for the $2000 \mathrm{ZCTA}$ areas.

${ }^{5}$ PCSAs are primary care physician markets derived from analysis of feefor-service (FFS) Medicare patient flows to primary care physician offices. These are natural preventive care markets, defined by Dartmouth
} 
including an index of high-tech service availability, whether the hospital is a major or minor teaching school, and staffed bed size are included. Contextual data are from the Area Resource File (ARF), the AHA survey of hospitals, and the U.S. Census, or derivations thereof.

\section{Analysis}

Multilevel logistic regression modeling of person-level hospital discharges for ACSCs and MCs was used to examine the effects of contractions in the California safety net on access by Medicaid and other vulnerable populations over the period of 1990-2000. When estimating the multilevel logistic model, we used SUDAAN with Generalized Estimating Equations (GEE) to control statistically for redundancy in contextual effects arising from individuals living in the same areas facing the same contextual variable (repeated measures). This allowed us to obtain robust estimates of the standard errors for the contextual variables so that we could accurately assess the statistical significance of observed differences in the predicted marginal probabilities. The predicted marginal probability of ACSC vS MC admission for each subgroup (i.e., race or ethnicity, insurance type, and proximity to $\mathrm{SNH}$ contraction event) was calculated by SUDAAN software as the average predicted response if all the observations had been in the given subgroup. To examine whether the difference in the predicted marginal probability between the two periods was statistically significant, we conducted bootstrapping with 200 repeated samples to obtain the standard error for the difference in predicted probabilities across time. We computed the $\mathrm{Z}$ statistic by dividing the difference in probabilities measure by the bootstrapped standard error. Because there were multiple comparisons for the $\mathrm{Z}$ statistic test among the subgroups, we used the Bonferroni adjustment to adjust the criteria of significance level for each set of comparisons.

We included both 'distance to the closest remaining SNH' and 'indicators of proximity to the nearest SNH contraction event' in both cross-sectional models, which are defined identically. The rationale for including distance to closest SNH that remained operational over the study period in addition to distance to contraction indicators is as follows. In 1990, the closest remaining $\mathrm{SNH}$, which was a stable institution present in both study years, is a resource for individuals, especially those near to it. More access impediments are likely to be present for those who live farther away from this SNH. Because it is stable over the study period, the distance to closest remaining $\mathrm{SNH}$ in either period has a level effect, telling us on average how an additional mile of separation is related to access. Including this level factor in each period allows us to control statistically for differences in the spatial layout of hospitals across the urban-rural continuum.

In addition to this level effect, we anticipated there would be a change effect. To gauge how access changed over 19902000 , it is necessary to hold constant statistically the variation in urban-rural travel distances via the 'distance to closest SNH' variable. With this variable in the model, we then used the proximity to contraction events (indicators D1

researchers for HRSA [46]. These areas are smaller and more numerous than counties, and have been validated in previous work [23, 47].
- D3) to compare residents in the same locations before and after these events. Estimated change effects are expected to include negative spillovers from one contraction event to other hospitals nearby. It is the combination of the level effects and change effects that tell the complete story regarding access impediment from SNH contraction.

\section{FINDINGS}

Sample statistics for the person-level data can be found in Table 2, where we see an increase over time in the number of ACSC and MC admissions, from 422,067 in 1990 to 472,570 in 2000, but the proportion of MCs remained stable, $19.2 \%$ vs $18.8 \%$ (Table 2 ). The proportion of sample members closest to a SNH contraction event (D1 threshold) decreased slightly over time (from 0.15 to 0.129 ) as might be expected with SNH closures over time. The age composition of the admissions was fairly similar over time, with a slight increase in the proportion of the oldest old, consistent with the aging population base. The proportion of female or black admissions was stable over time, while the proportion of Hispanic admissions rose from 0.124 to 0.168 . The Medicare payer group proportion increased over time from 0.549 to 0.601 , while Medicaid only increased slightly and the proportion of uninsured admissions dropped from 0.04 to 0.026 . The average number of co-morbidities per patient increased over time, as did the distance to the nearest SNH.

Table 3 shows that there is some variation in contextual factors at the hospital level, county level, and PCSA level. The Hispanic isolation index and area poverty rate increased over time, as did the mean travel time to work, while the proportion of recent foreign-born immigrants fell. The number of physicians and specialists per capita increased while the number of hospital inpatient days per capita decreased, reflecting growing reliance on outpatient care in the healthcare system.

We estimated two separate cross sections for the 1990 and 2000 periods, obtained the predicted marginal probability of ACSC admission $v s$ MC admission for the key categorical subgroup variables of interest (proximity to contraction event bands, insurance type/status, and race/ethnicity), and assessed whether changes over time in the predicted marginal probabilities associated with these subgroups were statistically significant. To thoroughly examine the changes over time that we believe were associated with erosion in the hospital safety net, we explored the relationships in the data using two separate regression specifications. Each had a different set of interaction effects and the same set of multilevel covariates. Model 1 included interaction of distance/proximity bands and insurance, and Model 2 interacted race or ethnicity and insurance type held by the patient.

We found that the overall interaction effect was significant in both models in both time periods, except for a marginally significant effect for the distance bands by insurance interaction in the late period $(\mathrm{p}=0.0732)$. In Figs. $(2,3)$, we present the predicted probabilities of ACSC relative to $\mathrm{MC}$ admissions, by various subgroups of interest. The higher predicted probabilities of ACSC relative to $\mathrm{MC}$ suggest impeded access to primary care services that, if available, may have prevented the ambulatory care sensitive 
Table 2. Sample Statistics (Mean and Standard Deviation) in California, 1990 and 2000, Person-Level Data for Persons with ACSC or MC Admissions

\begin{tabular}{|c|c|c|c|c|}
\hline & \multicolumn{2}{|c|}{1990} & \multicolumn{2}{|c|}{2000} \\
\hline Sample Size & \multicolumn{2}{|c|}{422,067} & \multicolumn{2}{|c|}{472,570} \\
\hline Proportion of ACSC admissions & 0.808 & 0.394 & 0.812 & 0.394 \\
\hline Proportion with D1=1 (close to event) & 0.150 & 0.357 & 0.129 & 0.335 \\
\hline Proportion with D2=1 (farther from event) & 0.161 & 0.368 & 0.156 & 0.363 \\
\hline Proportion with $\mathrm{D} 3=1$ (even farther from event) & 0.519 & 0.500 & 0.499 & 0.500 \\
\hline Age $35-44$ & 0.088 & 0.284 & 0.084 & 0.278 \\
\hline Age $60-64$ & 0.081 & 0.273 & 0.066 & 0.249 \\
\hline Age $65-69$ & 0.109 & 0.311 & 0.082 & 0.274 \\
\hline Age $70-74$ & 0.117 & 0.322 & 0.110 & 0.313 \\
\hline Age $75-79$ & 0.124 & 0.330 & 0.135 & 0.342 \\
\hline Age $80-84$ & 0.111 & 0.314 & 0.127 & 0.332 \\
\hline Age $85+$ & 0.127 & 0.333 & 0.173 & 0.378 \\
\hline Female & 0.560 & 0.496 & 0.568 & 0.495 \\
\hline Payer type: Uninsured & 0.040 & 0.195 & 0.026 & 0.159 \\
\hline Payer type: Other Insurance & 0.042 & 0.200 & 0.044 & 0.206 \\
\hline \# comorbidities & 1.028 & 0.948 & 1.388 & 1.028 \\
\hline distance to nearest $\mathrm{SNH}$ & 7.769 & 9.342 & 9.441 & 10.900 \\
\hline
\end{tabular}

hospitalization. The full regression results from which these are derived are presented in the Appendix 1, Tables 6A-7A.

Fig. (2) presents predicted marginal probabilities of ACSC vs MC from the first model where there is a two-way interaction between distance bands and insurance type. Table 4 below the figure presents the significance test for the change in the predicted marginal probabilities between the two time periods by distance band and insurance type. We see that in general the predicted probability of ACSC vs MC admission increased to various degrees over time along the distance bands continuum. For both Medicaid and Medicare insured individuals, the change in impeded access over time is higher in neighborhoods closest to a contraction event, and declines monotonically with distance to the event (across
D1, D2, D3). This increase over time suggests that Medicaid-insured residents living near to a safety net contraction event saw reduced access to primary care over the decade, with the impact being larger for those living closer to the contraction event, which was moderately significant for individuals living closest to contraction events $(\mathrm{P}$ value $=0.06)$. By contrast, the uninsured group shows a marked increase in probability of impeded access over time for residents living in all three distance bands and the increases were highly significant $(3.6 \%, 5.0 \%$, and $3.1 \%$ in D1, D2, and D3, respectively). This suggests that uninsured individuals faced increased impediments to access to care over time, regardless of their proximity to a $\mathrm{SNH}$ contraction event. 
Table 3. Sample Statistics (Mean and Standard Deviation) in California, 1990 and 2000, Hospital-, County-, and PCSA-Level Data

\begin{tabular}{|c|c|c|c|c|}
\hline \multicolumn{5}{|l|}{ Health Care System and Market Characteristics } \\
\hline & Mean & S. Dev. & Mean & S. Dev. \\
\hline Number of Hospitals (year) & \multicolumn{2}{|c|}{$418(1990)$} & \multicolumn{2}{|c|}{$360(2000)$} \\
\hline (Binary) provide high-tech & 0.438 & 0.497 & 0.253 & 0.435 \\
\hline (Binary) major teaching & 0.048 & 0.214 & 0.053 & 0.224 \\
\hline (Binary) minor teaching & 0.117 & 0.322 & 0.119 & 0.325 \\
\hline Total staffed beds & 185 & 149.33 & 192 & 145.37 \\
\hline Number of Counties (year) & \multicolumn{2}{|c|}{59 (1990) } & \multicolumn{2}{|c|}{$59(2000)$} \\
\hline Primary care physicians per thousand capita & 0.445 & 0.167 & 0.483 & 0.197 \\
\hline Specialist physicians per thousand capita & 0.395 & 0.344 & 0.496 & 0.395 \\
\hline Inpatient days per thousand capita (area demand) & 0.632 & 0.511 & 0.509 & 0.432 \\
\hline PAs, residents, and nurses per thousand capita & 0.721 & 0.245 & 0.576 & 0.896 \\
\hline \multicolumn{5}{|l|}{ Barriers, Facilitators, and Intervening Community Factors (PCSA) } \\
\hline Number of PCSAs (year) & \multicolumn{2}{|c|}{$328(1990)$} & \multicolumn{2}{|c|}{$335(2000)$} \\
\hline Isolation index, Black & 0.053 & 0.091 & 0.049 & 0.078 \\
\hline Isolation index, Hispanic & 0.248 & 0.211 & 0.310 & 0.234 \\
\hline Percent population in poverty & 0.136 & 0.089 & 0.154 & 0.097 \\
\hline Mean travel time to work & 22.766 & 6.699 & 27.717 & 8.022 \\
\hline Percent population foreign born, entering the US $1985-1990$ or $1995-2000$ & 0.218 & 0.128 & 0.146 & 0.079 \\
\hline
\end{tabular}

Fig. (2) also shows that persons with Medicaid insurance had the highest probabilities of ACSC vs MC admission in both time periods compared to other insurance groups, reaching almost $90 \%$ at every distance/proximity threshold and point in time. Medicaid insured persons had about 7$12 \%$ higher probabilities than uninsured persons in 1990, and about $5-7 \%$ higher probabilities than uninsured persons in 2000 (as the uninsured probabilities rose over time). This finding suggests that Medicaid insured individuals had persistently worse access to (or lower utilization of) primary services than other insured groups.

Fig. (3) shows differences in predicted probabilities of ACSC vs MC admission derived from model 2, which interacts insurance status and race or ethnicity. Table 5 presents the significance test of changes in predicted probabilities over time by insurance status and race or ethnicity. We see that increases in the probability of avoidable admissions over time are most prevalent for whites who are uninsured, increasing $4.9 \%$, followed by whites with Medicaid insurance $(0.9 \%)$ and whites with Medicare insurance $(0.4 \%)$. Whites with private insurance showed decreased ACSC probability after the contraction event, as did Hispanics with private insurance. There was a smaller increase for uninsured Hispanics $(2.3 \%)$, but this increase is not statistically significant using the stringent $\mathrm{p}<0.01$ level of significance that may be appropriate when taking into consideration multiple comparisons.
Table 4. Change Over Time in Predicted Marginal Probability (and in Standard Error), Z Statistic for Assessing Significance of the Change With p-Value, by Distance Bands Containing Closest SNH Contraction Events and Insurance Status

\begin{tabular}{|c|c|c|c|}
\hline & D1 & D2 & D3 \\
\hline \hline Uninsured & $0.036(0.013)$ & $0.050(0.014)$ & $0.031(0.007)$ \\
\hline $\mathrm{Z}$ & 2.681 & 3.562 & 4.668 \\
\hline p-value & 0.0073 & 0.0004 & 0.0001 \\
\hline Medicare & $0.015(0.003)$ & $0.011(0.003)$ & $-0.001(0.002)$ \\
\hline $\mathrm{Z}$ & 5.047 & 3.686 & -0.531 \\
\hline $\mathrm{p}$-value & $<0.0001$ & 0.0002 & 0.5954 \\
\hline Medicaid & $0.011(0.006)$ & $0.003(0.007)$ & $0(0.003)$ \\
\hline $\mathrm{Z}$ & 1.851 & 0.428 & 0.000 \\
\hline $\mathrm{p}$-value & 0.0642 & 0.6687 & 1.0 \\
\hline Private & $0.003(0.006)$ & $-0.002(0.005)$ & $-0.017(0.003)$ \\
\hline $\mathrm{Z}$ & 0.461 & -0.442 & -6.018 \\
\hline $\mathrm{p}$-value & 0.6448 & 0.6585 & $<0.0001$ \\
\hline
\end{tabular}


Comparable to our observations for Fig. (2), we find that Medicaid-covered individuals in each race and ethnicity subgroup had the highest probabilities of ACSC vs MC admission. This was evident for both the base and ending year of the study. Thus, worse access to primary care services appears to exist for all racial and ethnic subcategories relative to other insured groups, and this problem persisted over time.

\section{DISCUSSION}

This paper examines a traditional accessibility measure hospital admission for a preventable (avoidable) ACSC relative to a stable set of unavoidable MCs - using personlevel hospital discharge data to examine the effects of contractions in the California safety net on Medicaid and other vulnerable populations over the period 1990-2000. We used the estimation results to predict the probability of ACSC admission relative to the stable benchmark (MC admissions) for different population subgroups. These predicted marginal probabilities were then used to answer two research questions:

1. Are some population subgroups, in particular those covered by Medicaid, more deeply affected by the contraction of nearby safety net resources?

2. Over time, how does accessibility change for racial or ethnic subgroups with Medicaid and other types of insurance?

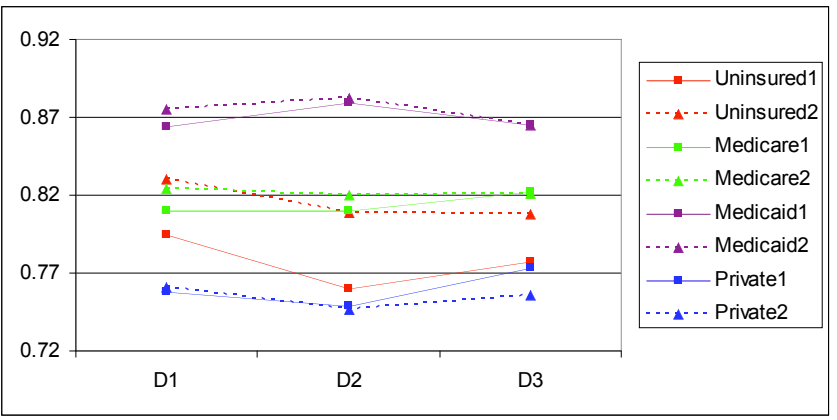

Fig. (2). Predicted marginal probability of ACSC vs MC admission from the interaction of distance bands containing closest $\mathrm{SNH}$ contraction events and insurance status, over time . D1 = closest $\mathrm{SNH}$ event within 6 miles; D2 = closest SNH event between 6-16 miles; D3 = closest SNH event between 16-46 miles. The dotted lines are period 2 (2000) and the solid lines are period 1(1990).

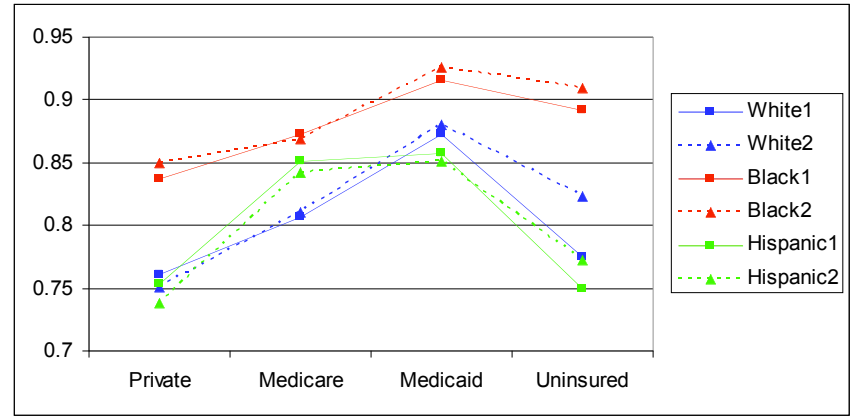

Fig. (3). Predicted marginal probability from the interaction of race or ethnicity and insurance type, over time. Legend: 1=1990; $2=2000$. The dotted lines are period 2 (2000) and the solid lines are period 1(1990).
For research question 1, we found that the Medicaid population subgroup was indeed affected more so than some of the other payer groups by the contraction of nearby safety net resources. Additionally, the results suggested that Medicare insured individuals who lived near a $\mathrm{SNH}$ contraction event also saw reduced access to care over time. The farther these types of individuals resided from a contraction event, the less it appeared to impact their access over time. In addition, we found that uninsured individuals had a large reduction in access over time whether they were near or far from SNH contraction events. It is unclear if this finding is driven by un-modeled factors for uninsured individuals living in the various distance bands. It is possible that those living nearby the contraction were impacted by the reduced safety net resources and that those living far away were impacted by reduced access to health care resources in general, including safety net and public or private health care resources.

For research question 2, we found that over time, accessibility changed in different ways for racial or ethnic subgroups by insurance type. Increases in the probability of avoidable admissions over time were most prevalent and statistically significant for whites with uninsured status followed by whites with Medicaid and whites with Medicare insurance type. The ACSC probability for uninsured Hispanics showed a small increase (about 2\%) that was not as highly significant as the finding for whites. Generally, the results indicated that Medicaid patients, regardless of race or ethnicity, had the highest rates of ACSC hospitalizations and these were persistent over time. Further, the data indicate that blacks had higher probability of access impediment than other racial and ethnic groups, and blacks with Medicaid or no insurance had even higher probabilities, in both time periods.

Our study used a Medicaid-based definition of $\mathrm{SNH}$ status and examined a natural experiment over time, wherein safety net resources contracted more severely in some communities than in others. We defined a "proximity to safety net contraction' variable at three different thresholds based on usual travel patterns to hospital, and control separately for the spatial layout of hospitals that yields different distances to SNHs along the urban-rural continuum. We examined proximity to this contraction event for different insurance types and racial or ethnic groups. We found that contraction in these $\mathrm{SNH}$ resources had a significant impact on access to care for people, not only those covered by Medicaid but also those with other insurance types.

Additionally, persons with Medicaid coverage exhibited higher probabilities of avoidable admissions than the uninsured for every racial or ethnic group. This is important for public policy today, because with the recent economic downturn nearly 6 million people were added to Medicaid enrollments. ${ }^{1}$ Also, the uninsured group (including both whites and Hispanics) saw the largest increases over time in access impediment. Although this group only increased by one-fourth the size of the Medicaid population over time, (i.e., 1.5 million), impeded access for this group and Medicaid populations is of considerable concern. Impeded access is associated with delayed care and often higher expenditures that would be necessary, compared to 
Table 5. Change Over Time in Predicted Marginal Probability (and in Standard Error), Z Statistic for Assessing Significance of the Change with p-Value, by Race or Ethnicity and Insurance Type

\begin{tabular}{|c|c|c|c|c|}
\hline & Private & Medicare & Medicaid & Uninsured \\
\hline White & $-0.011(0.003)$ & $0.004(0.001)$ & $0.009(0.003)$ & $0.049(0.006)$ \\
\hline $\mathrm{Z}$ & -4.307 & 3.091 & 2.621 & 7.605 \\
\hline $\mathrm{p}$-value & $<0.0001$ & 0.002 & 0.0088 & $<0.0001$ \\
\hline Black & $0.013(0.006)$ & $-0.004(0.004)$ & $0.010(0.005)$ & $0.017(0.011)$ \\
\hline $\mathrm{Z}$ & 2.168 & -0.996 & 2.087 & 1.551 \\
\hline $\mathrm{p}$-value & 0.0302 & 0.3193 & 0.0369 & 0.1209 \\
\hline Hispanic & $-0.016(0.005)$ & $-0.009(0.004)$ & $-0.006(0.005)$ & $0.023(0.010)$ \\
\hline $\mathrm{Z}$ & -3.011 & -2.489 & -1.324 & 2.285 \\
\hline p-value & 0.0026 & 0.0128 & 0.1855 & 0.0223 \\
\hline
\end{tabular}

individuals with good primary care. In these times of increasing budget deficits and cost-cutting it is important to realize that reduced access to these populations may save some funds in the short run, but add to mounting deficits in the long run.

There are of course limitations to our study that must be recognized. First, our primary data source is administrative data compiled by hospitals from discharge records and the shortcomings of these data have been noted in the literature [48]. In particular, racial and ethnic data recorded in these files likely are based on hospital personnel coding rather than self-reported by patients. Studies have found that selfreported racial and ethnic data are likely to be more accurate $[49,50]$. Despite this limitation though, hospital discharge data have been used extensively to study racial and ethnic disparities in health care delivery and outcomes [51], primarily because these data provide information on a large enough number of institutions that otherwise small population subgroups are adequately represented. Second, our study, like many others examining ACSCs and MCs, rely on hospital coding of patient diagnoses in patient discharge records. Zhan and Miller [48] note several reasons why coding errors might arise in this type of data given limited numbers of fields to record diagnoses and the fact that administrative data are more aligned with hospital billing than clinical completeness. However, the alternative to these data would be medical record extraction of information, which would lead one to study small numbers of institutions given the substantial costs of data collection and the problems noted above about small numbers of observations for particular population subgroups.

Another shortcoming of our study relates to our definition of SNHs. We identify SNH status in a baseline period for nonprofit hospitals, and there may be some degree of instability in hospital involvement in safety net activities, especially among nonprofit hospitals. Although annual reassessment of a nonprofit hospital's SNH status throughout our study period sounds attractive, this can only be done for those SNHs that remain operational throughout the period and not those that exit through closure or for-profit conversion. Also, our definition of nonprofit SNHs focuses on Medicaid caseload, which implies that our analysis is most relevant to the Medicaid population and the institutions on which they rely. Identification of potentially different groups of SNHs, based on hospital uncompensated care burden or SES in a hospital's market, could yield different patterns of effect based on patient populations most reliant on the identified SNHs. Finally, although we include a large number of community-contextual variables in our analysis, it may be that other community events or changes in local health systems are occurring that we cannot measure and are affecting hospitalization patterns in study communities.

Despite these limitations, our results suggest that the shrinking of safety net resources on access to care in nearby communities can have important effects on the local community, affecting not only Medicaid patients but people with different types of insurance coverage and different races or ethnicities. From a policy perspective, our research is timely given continued budget problems in many states and the Federal government and the deepening of the 2008 recession in 2009-2010. As the economy slows, unemployment rises and increasing proportions of people enroll in Medicaid or are left without health insurance. Our analyses demonstrate that contractions in the safety net along with increasing Medicaid and uninsured prevalence can have substantial impacts on access to care for vulnerable populations, which could result in potentially large increases in avoidable hospitalizations. The recently enacted Patient Protection and Affordable Care Act in the United States may help reverse some of these trends as more individuals obtain coverage through Medicaid expansions and insurance mandates. In addition, this law may ease the resource burdens on SNHs so that contraction events, such as the ones we studied, lessen in the future. However, our findings about the high rates of ACSC admissions even for those who have insurance, especially those covered by Medicaid, suggest that more focus on shoring up primary care resources in the United States will be important to reducing avoidable hospitalizations after health reform is implemented. 
APPENDIX 1: FULL REGRESSION RESULTS FOR CALIFORNIA FINDINGS IN FIGS. $(2,3)$

Table 6A. Factors Impacting the Odds of ACSC vs Marker Admission, with Two-Way Interaction of Distance Bands and Insurance Status, Over Time

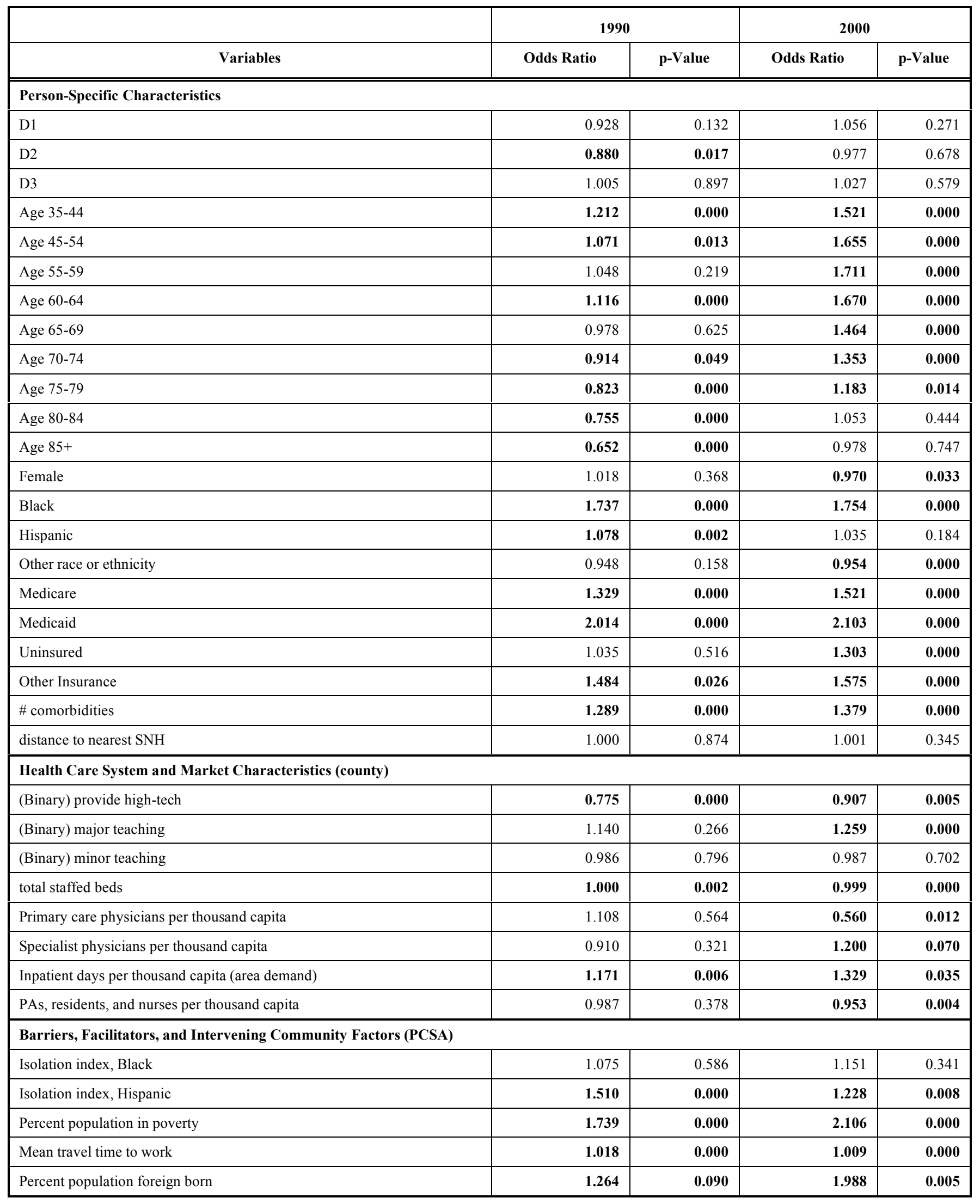




\begin{tabular}{|c|c|c|c|c|}
\hline \multirow[b]{2}{*}{ Variables } & \multicolumn{2}{|c|}{1990} & \multicolumn{2}{|l|}{2000} \\
\hline & Odds Ratio & p-Value & Odds Ratio & p-Value \\
\hline D1, Private & 1.000 & . & 1.000 & . \\
\hline D1, Medicare & 1.028 & 0.656 & 0.986 & 0.742 \\
\hline D1, Medicaid & 1.009 & 0.905 & 1.077 & 0.402 \\
\hline D1, Uninsured & 1.170 & 0.222 & 1.201 & 0.062 \\
\hline D1, Other & 1.221 & 0.251 & 1.144 & 0.250 \\
\hline D2, Private & 1.000 & . & 1.000 & . \\
\hline D2, Medicare & 1.093 & 0.064 & 1.035 & 0.406 \\
\hline D2, Medicaid & 1.152 & 0.161 & 1.241 & 0.014 \\
\hline D2, Uninsured & 0.980 & 0.836 & 1.121 & 0.206 \\
\hline D2, Other & 1.113 & 0.636 & 1.172 & 0.300 \\
\hline D3, Private & 1.000 & . & 1.000 & . \\
\hline D3, Medicare & 1.033 & 0.203 & 0.990 & 0.748 \\
\hline D3, Medicaid & 0.957 & 0.460 & 1.012 & 0.850 \\
\hline D3, Uninsured & 1.003 & 0.975 & 1.058 & 0.529 \\
\hline D3, Other & 0.995 & 0.969 & 1.011 & 0.892 \\
\hline D4, Private & 1.000 & . & 1.000 & . \\
\hline D4, Medicare & 1.000 & . & 1.000 & . \\
\hline D4, Medicaid & 1.000 & . & 1.000 & . \\
\hline D4, Uninsured & 1.000 & . & 1.000 & . \\
\hline D4, Other & 1.000 & . & 1.000 & . \\
\hline
\end{tabular}

Reference categories omitted from the table: age group 25-34; male; white; private insurance. Bolded odds ratios are statistically significant at the $95 \%$ level of confidence or better.

Table 7A. Factors Impacting the Odds of ACSC vs Marker Admission: Two-Way Interaction of Race or Ethnicity and Insurance Type, Over Time

\begin{tabular}{|c|c|c|c|c|}
\hline \multirow[b]{2}{*}{ Variables } & \multicolumn{2}{|c|}{1990} & \multicolumn{2}{|l|}{2000} \\
\hline & Odds Ratio & p-Value & Odds Ratio & p-Value \\
\hline \multicolumn{5}{|c|}{ Person-Specific Characteristics } \\
\hline D1 & 0.953 & 0.285 & 1.059 & 0.190 \\
\hline D2 & 0.935 & 0.138 & 1.018 & 0.678 \\
\hline D3 & 1.021 & 0.615 & 1.022 & 0.527 \\
\hline Age $35-44$ & 1.205 & 0.000 & 1.498 & 0.000 \\
\hline Age $45-54$ & 1.065 & 0.021 & 1.626 & 0.000 \\
\hline Age 55-59 & 1.041 & 0.277 & 1.680 & 0.000 \\
\hline Age 60-64 & 1.106 & 0.000 & 1.646 & 0.000 \\
\hline Age $65-69$ & 0.975 & 0.551 & 1.450 & 0.000 \\
\hline Age $70-74$ & 0.916 & 0.046 & 1.341 & 0.000 \\
\hline Age $75-79$ & 0.826 & 0.000 & 1.177 & 0.013 \\
\hline Age $80-84$ & 0.757 & 0.000 & 1.052 & 0.440 \\
\hline Age $85+$ & 0.653 & 0.000 & 0.978 & 0.738 \\
\hline Female & 1.021 & 0.317 & 0.971 & 0.044 \\
\hline Black & 1.630 & 0.000 & 1.926 & 0.000 \\
\hline
\end{tabular}




\begin{tabular}{|c|c|c|c|c|}
\hline \multirow[b]{2}{*}{ Variables } & \multicolumn{2}{|c|}{1990} & \multicolumn{2}{|c|}{2000} \\
\hline & Odds Ratio & p-Value & Odds Ratio & p-Value \\
\hline Hispanic & 0.960 & 0.133 & 0.937 & 0.043 \\
\hline Other race or ethnicity & 0.880 & 0.000 & 0.837 & 0.000 \\
\hline Medicare & 1.315 & 0.000 & 1.441 & 0.000 \\
\hline Medicaid & 2.172 & 0.000 & 2.519 & 0.000 \\
\hline Uninsured & 1.082 & 0.028 & 1.576 & 0.000 \\
\hline Other Insurance & 1.569 & 0.000 & 1.714 & 0.000 \\
\hline \# comorbidities & 1.287 & 0.000 & 1.376 & 0.000 \\
\hline distance to nearest SNH & 1.000 & 0.883 & 1.002 & 0.312 \\
\hline \multicolumn{5}{|c|}{ Health Care System and Market Characteristics (county) } \\
\hline (Binary) provide high-tech & 0.774 & 0.000 & 0.909 & 0.006 \\
\hline (Binary) major teaching & 1.138 & 0.286 & 1.257 & 0.000 \\
\hline (Binary) minor teaching & 0.989 & 0.840 & 0.989 & 0.760 \\
\hline total staffed beds & 1.000 & 0.002 & 0.999 & $\mathbf{0 . 0 0 0}$ \\
\hline Primary care physicians per thousand capita & 1.132 & 0.484 & 0.567 & 0.014 \\
\hline Specialist physicians per thousand capita & 0.903 & 0.280 & 1.194 & 0.076 \\
\hline Inpatient days per thousand capita (area demand) & 1.170 & 0.006 & 1.304 & 0.049 \\
\hline PAs, residents, and nurses per thousand capita & 0.988 & 0.384 & 0.953 & 0.004 \\
\hline \multicolumn{5}{|c|}{ Barriers, Facilitators, and Intervening Community Factors (PCSA) } \\
\hline Isolation index, Black & 1.099 & 0.466 & 1.185 & 0.233 \\
\hline Isolation index, Hispanic & 1.497 & 0.000 & 1.213 & $\mathbf{0 . 0 1 0}$ \\
\hline Percent population in poverty & 1.707 & 0.000 & 2.059 & 0.000 \\
\hline Mean travel time to work & 1.018 & 0.000 & 1.009 & 0.000 \\
\hline Percent population foreign born & 1.280 & $\mathbf{0 . 0 7 7}$ & 2.043 & 0.004 \\
\hline White, Private & 1.000 & . & 1.000 & . \\
\hline White, Medicare & 1.000 & . & 1.000 & . \\
\hline White, Medicaid & 1.000 & . & 1.000 & . \\
\hline White, Uninsured & 1.000 & . & 1.000 & . \\
\hline White, Other Insurance & 1.000 & . & 1.000 & . \\
\hline Black, Private Insurance & 1.000 & . & 1.000 & . \\
\hline Black, Medicare & 1.020 & 0.553 & 0.812 & 0.000 \\
\hline Black, Medicaid & 0.983 & 0.853 & 0.883 & 0.060 \\
\hline Black, Uninsured & 1.491 & 0.000 & 1.129 & 0.166 \\
\hline Black, Other Insurance & 1.358 & 0.004 & 1.090 & 0.305 \\
\hline HISP, Private & 1.000 & . & 1.000 & . \\
\hline HISP, Medicare & 1.441 & 0.000 & 1.337 & 0.000 \\
\hline HISP, Medicaid & 0.916 & 0.034 & 0.822 & 0.000 \\
\hline HISP, Uninsured & 0.903 & 0.348 & 0.766 & 0.002 \\
\hline Hispanic, Other Insurance & 0.950 & 0.407 & 0.942 & 0.269 \\
\hline Other race or ethnicity, Private Insurance & 1.000 & . & 1.000 & . \\
\hline Other race or ethnicity, Medicare & 1.301 & 0.000 & 1.326 & 0.000 \\
\hline Other race or ethnicity, Medicaid & 0.873 & 0.004 & 0.830 & 0.000 \\
\hline Other race or ethnicity, Uninsured & 0.862 & 0.117 & 0.863 & 0.172 \\
\hline Other race or ethnicity, Other Insurance & 0.886 & 0.052 & 0.921 & 0.316 \\
\hline
\end{tabular}




\section{REFERENCES}

[1] Institute of Medicine (IOM), Committee on the Changing Market, Managed Care, and the Future Viability of Safety Net Providers. America's health care safety net: intact but endangered. Washington, DC: National Academy Press 2000.

[2] Hellinger F. Tax exempt hospitals and community benefits: a review of state reporting requirements. J Health Polit Policy Law 2009; 34: 37-61.

[3] Gaskin DJ, Hadley J. Population characteristics of markets of safety-net and non-safety-net hospitals. J Urban Health 1999; 76: $351-70$.

[4] Hadley J, Cunningham P. Availability of safety net providers and access to care of uninsured persons. Health Serv Res 2004; 39: $1527-46$

[5] Gaskin DJ. Safety net hospitals: essential providers of public health and specialty services, New York City: The Commonwealth Fund, February 1999.

[6] Bazzoli GJ, Kang R, Hasnain-Wynia R, Lindrooth RC. An Update on the safety-net hospitals: coping with the late 1990s and early 2000s. Health Aff 2005; 24: 1047-56.

[7] Zuckerman S, Bazzoli GJ, Davidoff A, LoSasso AT. How have safety net hospitals coped during the 1990s? Health Aff 2001; 20: $159-68$.

[8] Cunningham PJ, O'Malley AS. Do reimbursement delays discourage Medicaid participation by physicians? Health Aff 2009; 28: $17-28$.

[9] Cunningham PJ, Hadley J. Effects of changes in incomes and practice circumstances on physicians' decision to treat charity and Medicaid patients. Milbank Q 2008; 86: 91-123.

[10] Felland LE, Hurley RE, Kemper NM. Safety net hospital emergency departments: creating safety valve for non-urgent care (Issue Brief No. 120). Washington, DC: Center for Studying Health System Change 2008.

[11] Meyer JA. Safety net hospitals: a vital resource for the United States. St. Louis, MO: Economic and Social Research Institute 2004.

[12] Cunningham PJ. What accounts for differences in the use of hospital emergency departments across US communities? Health Aff 2006; 25: 324-36.

[13] Medicare Prospective Payment Advisory Commission (MedPAC). Financial data report on Medicare providers. Washington, DC: MedPAC 2004.

[14] Baxter RJ, Mechanic RE. The status of local health care safety nets. Health Aff 1997; 16: 7-23.

[15] Holahan J, Zuckerman S, Evans A, et al. Medicaid managed care in thirteen states. Health Aff 1998; 17: 43-63.

[16] Mobley LR. Effects of selective contracting on hospital efficiency, costs, and accessibility. Health Econ 1998; 7: 247-61.

[17] Hurley R, Zuckerman S. Medicaid managed care: state flexibility in action. Assessing the new federalism discussion paper \#02-06. Washington, DC: The Urban Institute 2002.

[18] Dorn S, Garrett B, Holahan J, Williams A. Medicaid, SCHIP and economic downturn: policy challenges and policy responses. Prepared for the Kaiser Commission on Medicaid and the uninsured, April 2008; available from http://slides.kff.org/chart. aspx?ch $=360$

[19] Bazzoli GJ, Lindrooth RC, Kang R, et al. The effects of public policy and market forces on the hospital safety net. Health Serv Res 2006; 41: 1159-80.

[20] Lindrooth RC, LoSasso AT, Bazzoli GJ. The effect of hospital closure on markets. J Health Econ 2003; 22: 691-712.

[21] Khan AA, Bhardwaj SM. Access to health care: a conceptual framework and its relevance to health care planning. Eval Health Prof 1994; 17: 60-76.

[22] Aday L, Anderson R. A framework for the study of access to medical care. Health Serv Res 1974; 9: 208-20.

[23] Mobley LR, Kuo T, Andrews LS. How sensitive are multilevel regression findings to defined area of context? A case study of mammography use in California. Med Care Res Rev 2008; 65: 315-37. Available from: http://mcr.sagepub.com/cgi/content/abstract/ $65 / 3 / 315$ ?etoc.
[24] Mobley L, Kuo T, Driscoll D, Clayton L, Anselin L. Heterogeneity in mammography use across the nation: separating evidence of disparities from the disproportionate effects of geography. Int $\mathbf{J}$ Health Geogr 2008; 7: 32. Available from http://www.ijhealthgeographics.com/content/7/1/32.

[25] Cunningham P, Tu HT. A changing picture of uncompensated care. Health Aff 1997; 16: 167-75.

[26] Davidoff A, LoSasso AT, Bazzoli GJ, Zuckerman SM. The effects of changing state health policy on hospital uncompensated care. Inquiry 2000; 37: 253-67.

[27] Marquis MS, Rogowski JA Escarce JJ. Recent trends in geographic variation in the safety net. Med Care 2004; 42: 408-15.

[28] Thorpe KE, Seiber EE, Florence CS. The Impact of HMOs on hospital-based Uncompensated Care. J Health Polit Policy Law 2001; 26: 543-55.

[29] Fishman LE, Bentley JD. The evolution of support for safety net hospitals. Health Aff 1997; 16: 30-47.

[30] Gray, BH. Hospital ownership form and care of the uninsured. In: SH Altman, UE Reinhart, AE Shields, Eds. The future of the U.S. healthcare system: who will care for the poor and uninsured? Chicago: Health Administration Press 1998; pp. 207-22.

[31] Reuter J, Gaskin DJ. The role of academic health centers and teaching hospitals in providing care for the poor. In: SH Altman, UE Reinhart, AE Shields, Eds. The future of the U.S. healthcare system: who will care for the poor and uninsured? Chicago: Health Administration Press 1998; pp. 387-404.

[32] Atkinson G, Helms WD, Needleman J. State trends in hospital uncompensated care. Health Aff 1997; 16: 233-41

[33] Bazzoli GJ, Manheim LM, Waters TM. US hospital industry restructuring and the hospital safety net. Inquiry 2003, 40: 6-24.

[34] Gaskin DJ, Hadley J, Freeman VG. Are urban safety net hospitals losing low-risk Medicaid maternity patients? Health Serv Res 2001; 36(Part I): 25-51.

[35] Zwanziger J, Khan N. Safety net hospitals. Med Care Res Rev 2008; 65: 478-95.

[36] Institute of Medicine (IOM), Committee on Health Care Services. In: M Millman Ed. Access to health care in America. Washington DC: National Academy Press 1993.

[37] Weissman JS, Gatsonis C, Epstein AM. Rates of avoidable hospitalization by insurance status in Massachusetts and Maryland JAMA 1992; 268: 2388-94.

[38] Blustein J, Hanson K, Shea S. Preventable hospitalizations and socioeconomic status. Health Aff 1998; 17: 177-89.

[39] Culler SD, Parchman ML, Przyblski M. Factors related to potentially preventable hospitalizations among the elderly. Med Care 1998; 36: 804-17

[40] Basu J, Mobley L. Trends in racial disparities among the elderly for selected procedures. Med Care Res Rev 2008; 65(5): 617-37.

[41] Gaskin DJ, Hoffman C. Racial and ethnic differences in preventable hospitalizations across 10 states. Med Care Res Rev 2000; 57(Supplement 1): 85-107.

[42] Basu J, Clancy C. Racial disparity, primary care, and specialty referral. Health Serv Res 2001; 36(Part I): 64-77.

[43] Basu J, Friedman F, Burstin H. Primary care, HMO enrollment, and hospitalization for ambulatory care sensitive conditions: a new approach. Med Care 2002; 40: 1260-9.

[44] Billings J, Zeitel L, Lukomnik J, et al. Impact of socioeconomic status on hospital use in New York City. Health Aff 1993, 12: 16273.

[45] AHRQ. HCUP SID Database documentation: Healthcare Cost and Utilization Project (HCUP). Rockville, MD: Agency for Healthcare Research and Quality 2004. Available from www.hcupus.ahrq.gov/db/state/siddbdocumentation.jsp

[46] Goodman D, Mick S, Bott D, et al. Primary care service areas: a new tool for the evaluation of primary care services. Health Serv Res 2003; 38: 287-310.

[47] Mobley L, Root E, Anselin L, Gracia N, Koschinsky J. Spatial analysis of elderly access to primary care services. Int $\mathrm{J}$ Health Geogr 2006b; 5(1): 19. Available from: http://www.ij-healthgeogra phics.com/content/pdf/ 1476-072X-5-19.pdf 
[48] Zhan C, Miller MR. Administrative data based patient safety research: a critical review. Qual Saf Health Care 2003; 12(Supplement 2): ii58-63.

[49] Boehmer U, Kressin NR, Berlowitz DR, Christiansen CL, Kazis LE, Jones JA. Self-reported vs administrative race/ethnicity data and study results. Am J Public Health 2002; 92: 1471-2.
[50] Kressin NR, Chang BH, Hendricks A, Kazis LE. Agreement between administrative data and patients' self-reports of race/ethnicity. Am J Public Health 2003; 93: 1734-9.

[51] AHRQ. National healthcare disparities report, 2009. Rockville, MD: Agency for Healthcare Research and Quality 2009. Available from: http//:www.ahrq.gov/qual/nhdr09/nhdr09.pdf

Received: January 30, 2010

Revised: December 15, 2010

Accepted: March 1, 2011

(C) Mobley et al.; Licensee Bentham Open .

This is an open access article licensed under the terms of the Creative Commons Attribution Non-Commercial License (http://creativecommons.org/licenses/by$\mathrm{nc} / 3.0 /$ / which permits unrestricted, non-commercial use, distribution and reproduction in any medium, provided the work is properly cited. 